\title{
REFORÇO DO TRIÂNGULO INGUINAL COM ENXERTO DE FÁSCIA TRANSVERSAL - TÉCNICA
}

\author{
Inguinal triangular effort with a fascia transversalis graft - technique \\ Alcino Lázaro da SILVA
}

Trabalho realizado no Departamento de Cirurgia da Faculdade de Medicina da Universidade Federal de Minas Gerais, Belo Horizonte, MG, Brasil.

DESCRITORES - Fáscia. Hérnia inguinal. Recidiva.
RESUMO - Introdução - O esforço maior do cirurgião, na operação da hérnia inguinal, é prevenir a recidiva. Objetivo - Comunicar o uso de um retalho livre de fáscia transversal. Método - Operou-se um paciente, portador de hérnia inguinal direta, cuja fáscia transversal era extensa, espessa e elástica. Retirou-se um retalho em forma de calota que foi recolocado, sob a forma de enxerto, após o reforço clássico da fáscia transversal do triângulo inguinal. Resultado - Há dois anos sem recidiva. Conclusão - Sobre o reforço do triângulo inguinal pode-se colocar um enxerto da própria fáscia transversal se ela for exuberante.

\section{Correspondência:}

Alcino Lázaro da Silva,

e-mail: franciscoalberto@superig.com.br

Fonte de financiamento: não há

Conflito de interesses: não há

Recebido para publicação: 04/02/2010

Aceito para publicação: 09/03/2010

HEADINGS - Fascia. Hérnia inguinal. Recurrence.
ABSTRACT - Background - The physician's greatest effort at the inguinal hernia surgery is to prevent its recurrence. Aim - To communicate the use of free flap of "fascia transversalis" added to a triangular inguinal reinforcement. Methods - It was proceeded a surgery on a patient who carried a direct inguinal hernia, whose "fascia transversalis" was wide, thick and strechful. It was extracted one central round part of the fascia which was replaced as one free graft after the classical reinforcement of the triangular "fascia transversalis" inguinal. Result - In followup of two years there is no recurrence. Conclusion - A free graft from "fascia transversalis" when abundant may be used in surgery of inguinal hernia.

\section{INTRODUÇÃO}

A hérnia inguinal $(\mathrm{HI})$, como um reduto maior da cirurgia geral,

oferece desafios na sua reconstrução, no sentido de evitar um dos fantasmas do cirurgião que é a recidiva. Todos os cirurgiões sabem e aceitam ser a fáscia transversal ${ }^{1,2}$ o elemento mais importante, tanto na gênese como no reforço preventivo. As propostas e os procedimentos adotados, sempre que associados ao uso correto da fáscia, levam a um resultado melhor.

Adotamos como conduta a redução da hérnia, o aproveitamento da fáscia, eventualmente o uso de prótese sintética e, sempre que possível, o reforço com o saco herniário aberto e a face peritoneal para fora (Figura 1).

Os resultados são satisfatórios e nos induzem a persistir desde que poupamos o paciente de ficar com um corpo estranho.

\section{TÉCNICA}

Operamos um paciente, 60 anos, sadio, com hérnia inguinal direta bilateral em uso de funda há anos. Isto alargou o triângulo inguinal e fez com que a fáscia transversal se tornasse pouco espessa. À direita corrigimos a lesão e reforçamos com o saco herniário. À esquerda o anel era largo, não havia saco suficiente para produzir o enxerto e era um candidato a receber uma prótese. Trabalhando o tecido com maior observação a fáscia se apresentou espessa e elástica. Julgamos oportuno, então, aproveitá-la de duas formas: 


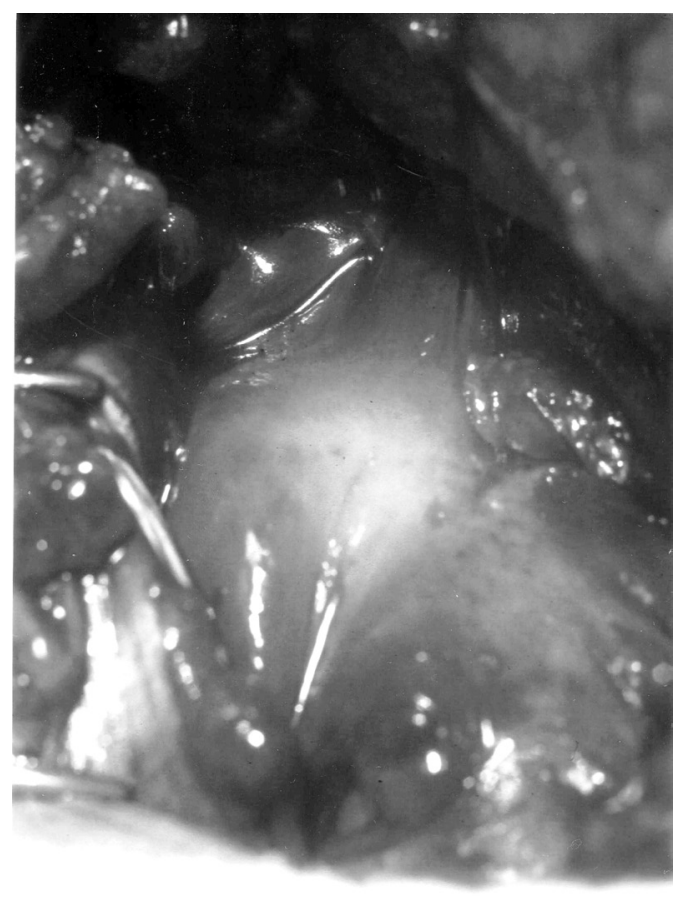

FIGURA 1 - Área inguinal exposta, após redução do saco herniário; sobre o reforço da fáscia transversal fixa-se a prótese biológica esticada retirando uma porção em forma de calota e fazendo o reforço do triângulo com a fixação dela aos ligamentos inguinal (Poupart) e iliopúbico (Thomson).

O tecido obtido, com alguns centímetros, foi suturado sobre o reforço, a exemplo de uma prótese sintética usada na rotina. Isto foi possível porque a fáscia se alargou e formou material suficiente para criação de um enxerto; era mais espessa, não era obesa e aceitou bem esticá-la e suturá-la, como na Figura 1.

Como não encontramos, até agora, nenhuma comunicação a esse respeito e tendo resultado imediato que nos satisfez, julgamos que seria útil comunicar o fato para repetirmos mais vezes esta alternativa.

\section{REFERÊNCIAS}

1. Silva AL. O uso do saco herniário no reforço da hernioplastia inguinal. Rev Col Bras Cir. 1995; 3:153-4.

2. Sousa PL, Silva AL. Emprego do saco herniário no reforço parietal nas hérnias inguinais indiretas do adulto. Rev Col Bras Cir. 1998; 25(3): 193-9. 